\title{
Transformações e tendências do mercado de trabalho no Brasil entre 2001 e 2015: paradoxo do baixo desemprego?
}

\author{
Pedro Henrique de Castro Simões* \\ José Eustáquio Diniz Alves ${ }^{*}$ \\ Pedro Luis do Nascimento Silva ${ }^{\star \star \star}$
}

\begin{abstract}
A economia brasileira, favorecida pelos superciclo das commodities, teve uma década de crescimento e relativa estabilidade macroeconômica, em que o mercado de trabalho apresentou um desempenho bastante favorável. Contudo, houve uma desaceleração do Produto Interno Bruto (PIB), seguida de forte recessão em 2015 e 2016. Houve uma defasagem grande entre o início da desaceleração da economia e seus primeiros efeitos sobre o mercado de trabalho, o chamado paradoxo do baixo desemprego. 0 objetivo deste artigo é analisar tal fenômeno, utilizando as duas principais pesquisas que abordam o tema emprego no âmbito do Instituto Brasileiro de Geografia e Estatística: a Pesquisa Nacional por Amostra de Domicílios e a Pesquisa Mensal de Emprego. Recorrendo à metodologia de decomposições da variação da taxa de desocupação, constatou-se que a parcela mais expressiva tanto da redução anterior da taxa de desocupação, quanto do seu aumento atual, ocorreu nas metrópoles, e que grande parte de seu comportamento pode ser explicado pela redução da participação dos mais jovens, das pessoas menos instruídas e pela redução no ritmo de inserção das mulheres no mercado de trabalho. 0 perfil etário da desocupação no país tornou-se mais jovem, o que traz preocupações quanto à emergência de uma "geração perdida".
\end{abstract}

Palavras-Chave: Mercado de trabalho. Desemprego. Juventude. Paradoxo do desemprego. Decomposição da taxa de desocupação.

\footnotetext{
* Escola Nacional de Ciências Estatísticas (Ence) do Instituto Brasileiro de Geografia e Estatística (IBGE), Rio de Janeiro-RJ, Brasil (pedro.simoes@slq.com.br).

** Escola Nacional de Ciências Estatísticas (Ence) do Instituto Brasileiro de Geografia e Estatística (IBGE), Rio de Janeiro-RJ, Brasil (jed_alves@yahoo.com.br).

*** Escola Nacional de Ciências Estatísticas (Ence) do Instituto Brasileiro de Geografia e Estatística (IBGE), Rio de Janeiro-RJ, Brasil (pedro.silva@ibge.gov.br).
} 


\section{Introdução}

0 trabalho é um direito fundamental e está intimamente ligado ao conceito de cidadania. 0 pleno emprego e o trabalho decente são bandeiras fundamentais da Organização Internacional do Trabalho (OIT) e a promoção do emprego é um dos principais objetivos da administração pública em todo o mundo.

A economia clássica considera o trabalho a principal fonte geradora de riqueza e um dos fatores indispensáveis na produção de bens e serviços. A relação entre o nível de atividade e o mercado de trabalho é fortemente estabelecida na teoria econômica, sendo a relação entre o emprego - representado pela taxa de desemprego - e o produto da economia descrita, na maior parte dos estudos, por meio de alguma variação da lei de Okun. ${ }^{1}$ Trata-se de uma equação que pode ser estimada econometricamente e estabelece uma relação matemática entre o crescimento do produto e a variação da taxa de desemprego (BLANCHARD, 2007). Numa economia operando normalmente, espera-se que haja uma relação negativa entre essas duas variáveis. Isto é, um aumento (redução) na taxa de crescimento do PIB deve levar a uma redução (aumento) na taxa de desemprego, com alguma defasagem que depende de características particulares de cada economia.

No Brasil, após uma década de relativa estabilidade macroeconômica, que propiciou crescimento do emprego e da renda, além de notáveis avanços sociais, houve perda de dinamismo da economia a partir de 2013 e uma profunda recessão em 2015 e 2016. Porém, houve uma defasagem significativamente grande entre o início do desaquecimento da economia e seus primeiros efeitos sobre o mercado de trabalho, o chamado paradoxo do baixo desemprego. Esta “demora" para que a fraqueza da economia fosse evidenciada nos indicadores de emprego foi alvo de intenso debate nos meios acadêmicos e na imprensa (GOLDFAJN, 2014; CORSEIUL, 2015).

De fato, o aquecimento do mercado de trabalho neste último ciclo de expansão da economia brasileira caracterizou-se pelo recuo do grau de informalidade e pela redução da taxa de desemprego aberto (ou taxa de desocupação, termo que doravante será utilizado). Segundo dados da Pesquisa Nacional por Amostra de Domicílios (PNAD), no Brasil, a taxa de desocupação entre as pessoas com dez anos ou mais de idade diminuiu de $9,7 \%$, em 2003 , para $6,2 \%$, em 2012 . Ainda que, a partir de 2013, tenha havido aumento nessa taxa (para 6,5\% em 2013 e 6,9\% em 2014), deve-se destacar que a tendência geral de queda se manteve no período de desaquecimento da economia que precedeu a atual recessão, especialmente em 2011 e 2012. Dados da Pesquisa Mensal de Emprego (PME), que reflete, em dados mensais, as condições de emprego em seis importantes regiões metropolitanas brasileiras, ${ }^{2}$ apresentam um quadro semelhante, com tendência de queda ainda mais

\footnotetext{
${ }^{1}$ A lei de Okun recebe este nome em homenagem a Arthur Okun, economista da equipe econômica do ex-presidente norteamericano John F. Kennedy, que, em 1962, estabeleceu as bases teóricas da relação inversa entre a variação do desemprego e do Produto Interno Bruto (PIB).

${ }^{2}$ A PME cobre as regiões metropolitanas de Belo Horizonte, Porto Alegre, Recife, Rio de Janeiro, Salvador e São Paulo.
} 
acentuada. De 12,3\% em 2003, a taxa de desocupação calculada para o total das áreas reduziu-se para 4,8\% em 2014, menor valor do período analisado. Em 2015, o indicador registrou aumento significativo, chegando a 6,8\%. Em fevereiro de 2016 (último mês da pesquisa) a taxa alcançou $8,2 \%$.

Nesse contexto, o objetivo do presente artigo é analisar as transformações do mercado de trabalho brasileiro entre 2001 e 2015 e descrever o paradoxo do baixo desemprego, à luz das transformações sociais, econômicas e demográficas a que esteve sujeita a força de trabalho no período de estudo. Para tal propósito, apresentam-se, em primeiro lugar, a estimação da lei de Okun e, posteriormente, a comparação das trajetórias das taxas de desocupação e atividade na PNAD e na PME. Em seguida, são expostos os resultados da decomposição da variação da taxa de desocupação no período, segundo duas metodologias distintas. Discute-se, ainda, como a crise do mercado de trabalho, em especial a baixa taxa de ocupação de jovens, prejudica o aproveitamento do bônus demográfico. Por fim, são apresentadas as conclusões.

\section{Paradoxo do baixo desemprego}

O fenômeno mais interessante do período analisado neste artigo ocorreu nos anos seguintes à crise financeira de 2008/2009, que atingiu proporções globais após o anúncio da quebra do banco norte-americano Lehman Brothers, em setembro de 2008, causando uma retração econômica no Brasil em 2009, que levou o PIB daquele ano a uma queda de 0,33\%. No entanto, a economia se recuperou rapidamente e, em 2010 - último ano do governo Lula -, registrou crescimento de 7,5\%. Desde o início do governo Dilma Rousseff, as taxas de crescimento do PIB caíram fortemente. Entretanto, as taxas de desocupação não subiram, pelo menos até 2012, no caso da PNAD, e até 2014, segundo a PME, passando a refletir o desaquecimento da economia em curso somente em 2015. Tal fenômeno - a manutenção de baixas taxas de desocupação num cenário de baixo crescimento econômico - foi denominado, por muitos estudiosos e jornalistas especializados, de "paradoxo do baixo desemprego" ou "paradoxo do mercado de trabalho" e suscitou um grande debate que, sob diversos aspectos, ainda está em aberto.

A tendência declinante da taxa de desocupação durante a maior parte do período coberto por este trabalho foi pouco afetada pelas variações no crescimento da economia. Entretanto, quando se passa a analisar a variação dessa taxa, um comportamento contra cíclico pode ser observado. Por mais que a comparação entre um indicador de abrangência nacional (o PIB) e outro que envolve somente as mais importantes metrópoles do país (a taxa de desocupação pela PME) seja problemática, esta é a melhor maneira - senão a única, até o começo da divulgação da PNAD contínua - de realizar um acompanhamento conjuntural das estatísticas de trabalho no Brasil, e é amplamente utilizada.

A fim de evidenciar o comportamento particular da taxa de desocupação entre 2012 e 2014, estimou-se uma lei de Okun para verificar como se comporta o ajuste dos pontos 
associados ao período do paradoxo em relação à reta estimada. Para a regressão, foram utilizadas as séries de índice de volume trimestral do PIB a preços de mercado e a taxa de desocupação da PME. Empregando o critério de melhor ajuste segundo indicado pelo coeficiente de determinação, escolheu-se a especificação em que os efeitos do nível de atividade se dão com um trimestre de defasagem. Dessa maneira, a equação de regressão linear estimada foi:

$\Delta$ Desoc $_{t}=-0,27 \Delta P I B_{t-1}+0,46$

Em que:

$t$ denota o trimestre;

$\triangle D e s o c$ é a variação da taxa de desocupação;

$\triangle P I B$ é a variação percentual do PIB contra o mesmo trimestre do ano anterior.

O Gráfico 1 exibe os resultados deste exercício. Há, claramente, uma relação forte e negativa entre as duas séries. Isto é, de acordo com o que se poderia esperar pela teoria, trimestres de expansão da economia são, geralmente, marcados por redução da taxa de desocupação, enquanto trimestres de baixo crescimento ou retração econômica são acompanhados de aumento do mesmo indicador (DORNBUSCH; FISCHER, 2006). Pontos à esquerda ou abaixo da reta estimada indicam trimestres em que, dado um valor para o crescimento do PIB, a variação na taxa de desocupação foi menor do que se esperaria pela relação econométrica estimada.

\section{GRÁFICO 1}

Diagrama de dispersão entre a taxa de crescimento anual do PIB trimestral (Brasil) e a variação anual da taxa de desocupação (Regiões metropolitanas da PME') - 1ํㅡㄹ trimestre 2003 ao $4^{\circ}$ trimestre de 2015

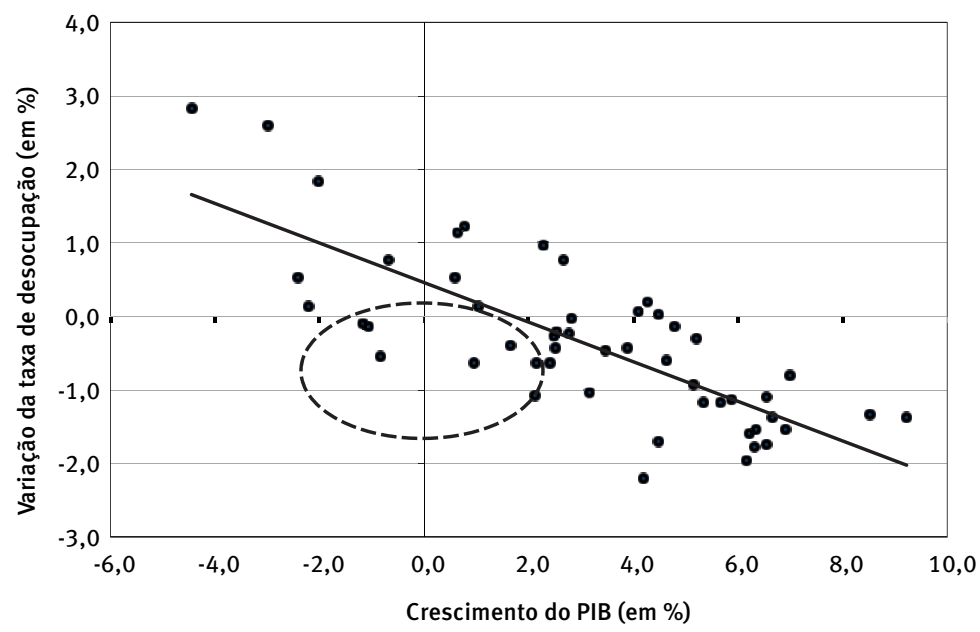

Fonte: IBGE. Pesquisa Mensal de Emprego (PME) e Sistema de Contas Nacionais Trimestrais.

(1) Belo Horizonte, Porto Alegre, Recife, Rio de Janeiro, Salvador e São Paulo.

Os pontos na área demarcada com um círculo no Gráfico 1 representam trimestres em que, apesar do crescimento relativamente baixo (menor que 2,5\%), a taxa de desocupação caiu mais do que se esperava. Dentre estes pontos estão todos os quatro trimestres de 
2012 e três trimestres de 2014. Os demais são trimestres de 2009, ano em que a crise financeira internacional atingiu o Brasil. Há, portanto, um comportamento pouco usual na relação entre a taxa de desocupação da PME e o crescimento do PIB entre 2012 e 2014.

Com o objetivo de melhor estudar tal fenômeno, analisaram-se as taxas de desocupação e de atividade para grupos de interesse, com base em características sociais, demográficas e econômicas da força de trabalho nas duas principais pesquisas que abordam o mercado de trabalho no Brasil, a PME e a PNAD, comparando-as adequadamente entre 2001 e 2015.

\section{Evolução das taxas de atividade e desocupação}

É importante estabelecer previamente alguns conceitos e critérios para a comparação das taxas de atividade e desocupação nos dois levantamentos, PNAD e PME. A utilização das duas pesquisas se justifica pelo fato de a primeira refletir os dados nacionais, mas com informações até 2014, enquanto a PME, apesar de representar as regiões metropolitanas, disponibiliza dados mais recentes, quando o mercado de trabalho mostra uma inflexão importante. ${ }^{3}$

A taxa de atividade (ou taxa de participação) é calculada como a razão entre a população economicamente ativa (PEA) e a população em idade ativa (PIA). ${ }^{4}$ Aqui, opta-se por considerar a população em idade ativa aquela com dez anos ou mais, visto que o interesse é analisar a população que está ocupada ou procurando emprego. ${ }^{5} \mathrm{~A}$ PEA é um subgrupo da PIA, composto pelas pessoas classificadas como ocupadas e desocupadas. A taxa de atividade pode ser entendida como uma medida do tamanho relativo da força de trabalho, sendo assim uma aproximação do volume da oferta de trabalho disponível para ser empregada nas atividades econômicas.

Já a taxa de desocupação é calculada como a razão entre o número de pessoas desocupadas na semana de referência e a PEA no mesmo período. Ela pode ser entendida como uma medida das condições de aquecimento do mercado de trabalho, já que mensura, ainda que com diversas limitações, ${ }^{6}$ a proporção de pessoas economicamente ativas que não conseguem encontrar ocupação.

Para que seja estabelecida uma comparação mais apropriada entre ambas as pesquisas, duas questões principais devem ser consideradas. A primeira é a diferença na abrangência geográfica. É possível construir, com os dados da PNAD, um recorte geográfico que a restringe exatamente às mesmas regiões metropolitanas cobertas pela PME. Dessa maneira, foram calculados também os resultados para as RMs da PME segundo dados da

\footnotetext{
${ }^{3}$ Vale registrar que as duas pesquisas, no formato usado até então, foram encerradas: a PNAD em 2015 e a PME em fevereiro de 2016. A PNAD Contínua substitui ambas com nova metodologia.

${ }^{4}$ Recentemente, o IBGE passou a utilizar o termo "população em idade de trabalhar" em suas publicações, mas, neste artigo, optou-se por manter a nomenclatura tradicional.

${ }^{5}$ A Organização Mundial do Trabalho (OIT) recomenda considerar como PIA a população de 15 anos ou mais, no entanto, o grupo de 10 a 14 anos praticamente não altera a taxa.

${ }^{6}$ Ver, por exemplo, Neri (2002) e Banco Central do Brasil (2012).
} 
PNAD e para o restante do Brasil sem essas regiões, pela mesma pesquisa. Outra questão a ser considerada é a diferença na periodicidade dos dois levantamentos. 0 cálculo de um padrão médio de sazonalidade para os dois indicadores com dados da PME entre 2003 e 2015 revela que a utilização do mês de setembro para representar o ano na comparação da PME com a PNAD é adequada, pois, no que diz respeito às taxas de desocupação, o mês de referência da PNAD (setembro) é exatamente aquele que melhor representa o ano na $\mathrm{PME}$, enquanto para a taxa de atividade os desvios médios em relação à média anual para todos os meses - incluindo setembro - são muito pequenos, isto é, há pouca influência da sazonalidade.

O Gráfico 2 compara as trajetórias das taxas de desocupação agregadas nas duas pesquisas segundo os critérios anteriormente descritos. Observa-se que a queda da taxa de desocupação é mais intensa na PME, levando a uma mudança marcante na relação das taxas de desocupação das duas pesquisas. Até 2008, a taxa da PME apresentava-se sistematicamente maior do que a da PNAD, situação que se inverteu a partir de 2009. Também é possível verificar nos dados um fenômeno conhecido na literatura sobre a taxa de desocupação: ela tende a ser maior nas metrópoles, mesmo que seja fato muito difundido que estas são regiões economicamente mais dinâmicas. Quando a amostra restrita às regiões metropolitanas da PME é separada do restante do país nos dados da PNAD, constata-se, para todo o período abordado, que a taxa de desocupação é sempre maior nas RMs do que no restante do país. ${ }^{7}$ A explicação para isso pode estar nas pressões de oferta a que estão sujeitas as pessoas economicamente ativas nas metrópoles, resultado de fluxos migratórios e concentração populacional (CORSEUIL; RAMOS, 2014) ou, então, de uma maior exigência de qualificação por parte dos empregadores nas regiões metropolitanas.

GRÁFICO 2

Taxas de desocupação e de atividade, por recorte geográfico e pesquisa Brasil e regiões metropolitanas da PME - 2001-2015
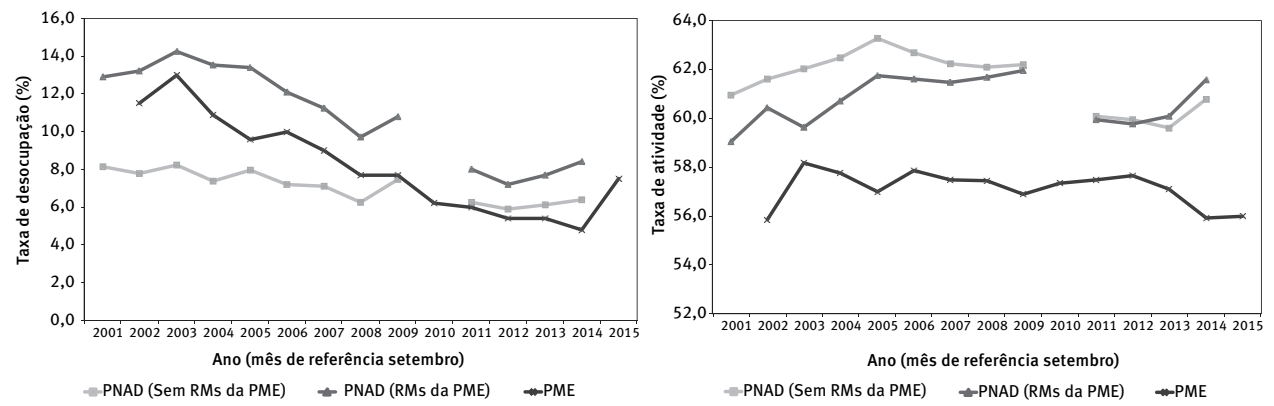

Fonte: IBGE. Pesquisa Nacional por Amostra de Domicílios e Pesquisa Mensal de Emprego.

De fato, os dados também revelam que a PNAD restrita à mesma abrangência geográfica da PME não é uma boa aproximação da própria PME, outro resultado já sugerido

\footnotetext{
${ }^{7}$ Fato que já havia sido registrado em estudo anterior (RAMOS, 2007) e que se manteve, ainda que os diferenciais tenham diminuído.
} 
na literatura. ${ }^{8}$ Não apenas este recorte apresenta taxas sempre superiores às da própria PME, como a sua dinâmica guarda mais similaridades com a PNAD agregada do que com a PME, visto que essa diferença se ampliou a partir de 2013, quando a taxa de desocupação passou a crescer tanto na PNAD quanto na PNAD restrita às RMs da PME, mas continuou a cair no levantamento mensal.

Apesar das diferenças supracitadas, em um ponto a PME e a PNAD restrita às suas regiões metropolitanas contam histórias parecidas: a maior parte da redução da taxa de desocupação no mais recente ciclo de expansão da economia brasileira aconteceu nas metrópoles. Pelos dados da PNAD, entre 2003, ano em que a taxa de desocupação atingiu o ponto mais alto no período analisado (9,7\%), e 2012, quando alcançou o menor patamar $(6,2 \%)$, a taxa medida nas regiões metropolitanas da PME caiu quase pela metade, de $14,2 \%$ para $7,2 \%$, uma expressiva redução de 7,0 pontos percentuais. Enquanto isso, no restante do país, a queda da taxa de desocupação foi muito mais modesta, de 8,2\% para $5,9 \%$, entre 2003 e 2012, um total de 2,4 pontos percentuais. Considerando que o peso da população em idade ativa das regiões metropolitanas da PME na PIA do Brasil permaneceu praticamente inalterado no período (ao redor de $25 \%$ ), é possível afirmar que, apesar de representarem apenas $1 / 4$ da PIA do país, as regiões metropolitanas da PME foram responsáveis por exatamente metade da queda de 3,5 pontos percentuais observada na taxa agregada de desocupação entre 2003 e $2012 .{ }^{9}$

Dito de outro modo, a taxa de desocupação caiu mais onde ela era maior, mas também é nessas mesmas áreas que este indicador está subindo mais com os impactos da atual crise - tanto no recorte PME da PNAD, até 2014, quanto na PME, em que a taxa saltou para 7,6\% em 2015, nível mais alto desde 2009. Uma possível explicação para este comportamento das taxas de desocupação desagregadas entre metrópoles e demais regiões pode estar ligada ao fato de que, nas cidades menores, o grande peso das transferências governamentais, os aumentos reais do salário mínimo e a importância dos gastos em programas sociais - que apresentaram crescimento robusto no período analisado neste trabalho -, fazem com que a economia nessas localidades seja menos sensível às flutuações macroeconômicas quando comparada à economia nas metrópoles (RIBEIRO, 2016). É interessante destacar que esta hipótese, aqui levantada, não está em desacordo com a ideia de que as metrópoles tiveram uma redução maior em suas taxas de desocupação por terem economias mais dinâmicas. Contrariamente, ela reafirma esta proposição ao considerar a existência de uma simetria: a maior sensibilidade às condições gerais da economia nas metrópoles vigoraria tanto nos momentos de expansão quanto nos de retração da economia, fazendo com que as flutuações na taxa de desocupação sejam maiores nessas áreas do que no restante do país.

\footnotetext{
$\overline{8}$ Ver, por exemplo, Barbosa Filho e Pessôa (2011). Uma comparação entre as taxas de desocupação da PNAD limitada às regiões metropolitanas cobertas pela PME, utilizando a mesma definição de ocupação, o mesmo recorte geográfico e a mesma composição da PEA por sexo, idade e educação, mostra que as diferenças nos níveis da taxa de desocupação entre as duas pesquisas permanecem mesmo com todos estes controles (CORSEUIL; RAMOS, 2014).

${ }^{9}$ As contas: $0,75 * 2,35+0,25 * 7,03=1,76+1,76=3,52$.
} 
A taxa de atividade no período de interesse deste trabalho apresenta tendências marcantes (Gráfico 2). Seguindo movimento que vinha pelo menos desde 1996 (BARBOSA, 2014a), do ano de 2001 até 2005 este indicador apresentou tendência ascendente segundo os dados da PNAD. De 2006 a 2009 a tendência é de queda. 0 que salta aos olhos ocorreu entre 2009 e 2011: uma queda abrupta ${ }^{10}$ de mais de 2,0 p.p., que continuou, ainda que de maneira mais suave, em 2012 e 2013, quando a taxa de atividade atingiu 59,7\%. Em 2014 este indicador cresceu mais de um ponto percentual, chegando a $61 \%$. Um aumento simultâneo e generalizado das taxas de desocupação e de atividade, portanto, marcou o ano de 2014. Isso indica que os efeitos da crise começaram a se fazer sentir mais fortemente apenas três anos após o começo da desaceleração da economia, ainda que a taxa de desocupação pela PNAD tenha subido já na passagem de 2012 para 2013. Com os primeiros efeitos da crise, a renda familiar deixou de crescer ou mesmo se reduziu, e mais pessoas sentiram necessidade de se inserir no mercado de trabalho. Entretanto, a economia menos aquecida tende a gerar menos empregos e, com isso, há maior dificuldade para encontrar ocupação, pressionando a taxa de desocupação.

Os dados da PME relativos à taxa de atividade apresentam marcante estabilidade na maior parte do período analisado, com uma tendência de queda mais clara apenas entre 2012 e 2014 e estabilidade em 2015, quando a taxa chegou aos 56\%. Seus níveis são muito mais baixos do que em qualquer recorte da PNAD. Para os anos iniciais do período, o recorte das RMs da PME na PNAD apresentava uma taxa de atividade mais baixa do que a das demais áreas, aproximando-a da PME, como se esperaria. No entanto, essa diferença diminui ao longo do período analisado, é praticamente nula entre 2009 e 2012 e se inverte a partir de 2013: desde então, o recorte PME na PNAD indica uma taxa de atividade maior do que para o restante das áreas, o que está em total desacordo com o que aconteceu na própria PME. Novamente, o recorte geográfico das RMs da PME na PNAD não parece ser uma boa aproximação da própria PME.

É importante mencionar que a diferença no comportamento dos indicadores entre as duas pesquisas, mesmo quando restritas às mesmas regiões, não é apenas em nível. Recentemente, a diferença tem sido também de indicações qualitativas. É necessária uma investigação mais profunda sobre possíveis fontes adicionais de divergências entre as duas pesquisas, focando nas diferenças metodológicas e em seus elementos de trabalho de campo, tais como as orientações dadas aos entrevistadores, o fluxo do questionário e a ordem em que são feitas as perguntas. 0 esquema amostral da PME, por exemplo, é bastante diferente do da PNAD (CORSEUIL; REIS, 2015). Há, ainda, alguns estudos que indicam que a PME pode subestimar o número de desocupados (PAIM, 2016). Se, de fato, a PME estiver subestimando o número de desocupados classificando-os como inativos,

\footnotetext{
10 Barbosa (2014a) pondera que essa queda abrupta na taxa de atividade da PNAD na passagem de 2009 para 2011 possa ser atribuída aos diferentes planos amostrais adotados. A PNAD 2009 usa como base os municípios amostrados com o Censo Demográfico de 2000, enquanto a de 2011 baseou-se na amostra obtida no Censo Demográfico de 2010. Entretanto, a questão ainda requer análise mais detalhada.
} 
esta poderia ser uma explicação para a queda abruta da taxa de atividade nesta pesquisa, especialmente na passagem de 2013 para 2014, enquanto a PNAD, mesmo quando restrita à mesma abrangência da $\mathrm{PME}$, vai em direção oposta.

A esta queda abrupta da taxa de atividade da PME associa-se grande parte do chamado paradoxo do baixo desemprego, que marcou a economia brasileira entre 2012 e 2014. Como a PME era uma pesquisa muito observada conjunturalmente - por ter frequência mensal -, o paradoxo do mercado de trabalho ganhou muito destaque. Os agentes não estão errados em fazê-lo, afinal, a PME representa a melhor aproximação do estado do mercado de trabalho para o Brasil disponível mensalmente e em curto prazo para análise. Os dados da PNAD costumam ser divulgados apenas em meados do segundo semestre do ano seguinte, dificultando seu uso em análises conjunturais e, na verdade, a taxa de desocupação aumentou na PNAD no período do paradoxo. Foi a taxa de desocupação medida pela PME que permaneceu em queda; tanto é assim que praticamente todos os estudos e reportagens que abordam o tema usam, como referência, a pesquisa mensal.

As explicações para a redução da taxa de atividade com baixa taxa de desocupação são diversas, e nenhuma aparenta ser definitiva. As mais comumente apontadas são as que associam a dinâmica atual do mercado de trabalho às transformações socioeconômicas da última década, ao padrão recente de crescimento da economia brasileira, muito ligado ao setor de serviços, e, finalmente, às mudanças demográficas pelas quais tem passado a população brasileira. Da primeira explicação, pode-se dizer que o significativo crescimento da renda das famílias verificado nos últimos anos, as políticas sociais ativas e um maior acesso à formação educacional e profissional teriam tornado o ingresso no marcado de trabalho, principalmente para os jovens, mais opção e menos necessidade. Com o rendimento mais elástico, membros da unidade familiar que, por qualquer razão, tenham tendência a não ofertar trabalho, se sentem mais à vontade para não fazê-lo. Dados do Ministério da Educação revelam que o número de estudantes universitários no Brasil saltou de quase 4,0 milhões, em 2003, para mais de 7,3 milhões, em 2013, um expressivo crescimento de $83 \%$ em dez anos.

Além disso, nos últimos anos, acumulam-se evidências do aumento da parcela de jovens brasileiros que não estudam e nem trabalham, os chamados "nem-nem", o que também atuaria no sentido da retração da PEA, um fenômeno que vem preocupando formuladores de políticas públicas em todo o mundo, podendo ter consequências sociais e econômicas sérias (IBGE, 2012).

Autores que se dedicaram a estudar a influência da ampliação da cobertura de programas de transferência de renda sobre a taxa de atividade concluem que não se pode afirmar que o aumento de pessoas beneficiadas a tenha alterado significativamente (TEIXEIRA, 2009; BRITTO; MEDEIROS; SOARES, 2008).

Bicalho (2013), ao se debruçar sobre o paradoxo do baixo desemprego com atividade fraca, indica, enquanto razões fundamentais por trás do fenômeno, fatores demográficos, como o crescimento menor da oferta de trabalhadores, e uma demanda forte de mão de obra por parte do setor de serviços. A redução no ritmo de crescimento populacional já estaria se 
fazendo sentir na economia brasileira. Além do próprio fator cíclico (a economia fraca que poderia desestimular muitas pessoas a procurarem um emprego, deixando de ingressar ou mantendo-se fora da PEA), o autor chama atenção para o fato de que o crescimento econômico no Brasil recentemente foi maior no setor de serviços, que, por ser intenso em mão de obra, foi responsável por cerca de $80 \%$ a $90 \%$ da criação de empregos nos últimos anos.

A desagregação das taxas de desocupação e de atividade segundo algumas características sociodemográficas da força de trabalho revela alguns fatos importantes. A desagregação por sexo (Gráfico 3) mostra que a taxa de desocupação apresenta desigualdades marcantes no nível, sendo bastante superior para as mulheres. Sua queda foi grande para ambos os sexos, mas não idêntica, pois ocorreu mais tardiamente para as mulheres, além de ter sido menos intensa para elas. Tal diferença de comportamento foi maior nas regiões metropolitanas da PME.

\section{GRÁFICO 3}

Taxas de desocupação e de atividade, por sexo, segundo recorte geográfico e pesquisa Brasil e regiões metropolitanas da PME - 2001-2015
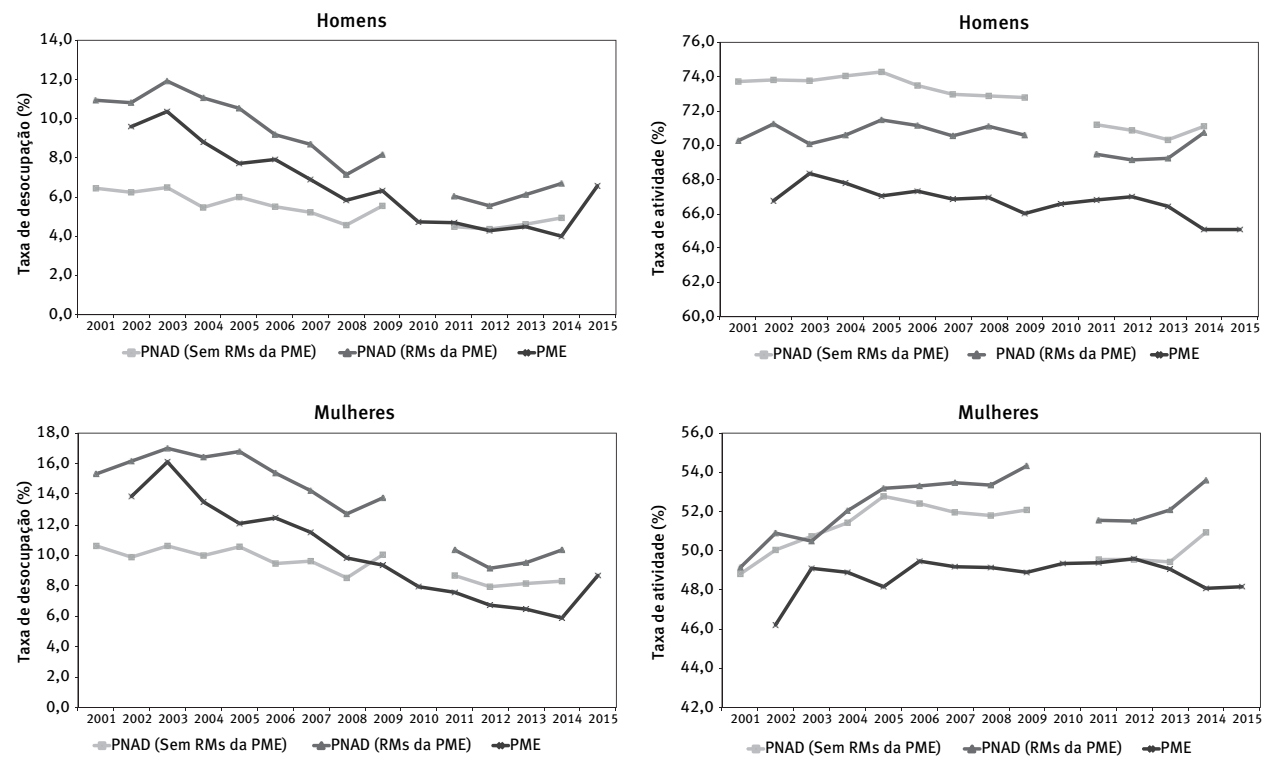

Fonte: IBGE. Pesquisa Nacional por Amostra de Domicílios e Pesquisa Mensal de Emprego.

A taxa de atividade dos homens é maior do que a das mulheres para todos os anos, recortes geográficos e pesquisas analisados, sendo que esta diferença tende a ser menor nas regiões metropolitanas. A taxa de atividade das mulheres apresentou clara tendência de aumento até 2005-2006, seguindo um movimento de longo prazo (BARBOSA, 2014b). Entretanto, houve uma inflexão nessa tendência, e a taxa passou a cair até 2013, só voltando a crescer com o advento da crise econômica. Também seguindo uma tendência histórica, a taxa masculina mostrou tendência geral de queda, principalmente a partir de 2005, igualmente revertida apenas com os primeiros efeitos da crise econômica. 
A desagregação das taxas de desocupação e atividade por idade (Gráfico 4) mostra que a queda da taxa de desocupação foi generalizada entre os grupos etários, mas muito mais intensa para os mais jovens, as pessoas de 10 a 24 anos. Em 2014, a desocupação cresceu em todas as faixas de idade, exceto para os mais velhos. Estes já apresentam uma taxa geralmente baixa, mas ela atingiu, neste ano, o menor patamar da série. Isso poderia ser explicado pelo fato de que as pessoas com mais idade só se dispõem a ofertar trabalho quando já existe certeza do emprego, ainda mais quando as condições do mercado não são favoráveis.

A taxa de atividade tendeu a cair mais para as pessoas mais novas e mais velhas (Gráfico 4) e a aumentar ou se manter estável nas idades intermediárias. Há um comportamento anticíclico na participação dos jovens em relação ao crescimento da economia, algo que não é observado no grupo etário em que se encontram as pessoas no auge do período ativo (entre 25 e 49 anos).

A desagregação por anos de estudo ${ }^{11}$ mostra que a taxa de desocupação tende a ser menor nos extremos do nível de instrução, isto é, entre as pessoas com pouquíssima ou elevada escolaridade, e mais alta entre aquelas de escolaridade intermediária. A taxa diminuiu mais entre aqueles para quem ela já era mais alta, isto é, para os níveis de instrução intermediários, especialmente para as pessoas com 1 a 7 anos de estudo, que configuram aquelas sem ensino fundamental completo. Para as pessoas mais instruídas, com 15 anos ou mais de estudo, isto é, com ensino superior completo, a taxa de desocupação, além de baixa, praticamente não flutuou, indicando pouca sensibilidade em relação às condições macroeconômicas.

Entretanto, na passagem de 2013 para 2014, houve aumento da taxa de desocupação para todos os níveis de instrução, com exceção das pessoas na extremidade inferior da escolaridade. De fato, em 2014, pela primeira vez, as pessoas com baixíssima ou nenhuma instrução apresentaram uma taxa de desocupação inferior à daquelas mais instruídas, considerando o total do Brasil. Isso pode estar associado a dois fenômenos. Primeiro, a análise da composição etária da PIA permite ver que este grupo, juntamente com o das pessoas com 1 a 3 anos de educação, teve sua participação fortemente reduzida ao longo do período de análise. Isto é, diminuiu a oferta de trabalhadores menos qualificados no país e aumentou a daqueles mais qualificados. A participação das pessoas em idade ativa com pelo menos o ensino médio completo (11 ou mais anos de estudo) correspondia a pouco mais de $20 \%$ da PIA brasileira em 2001, ampliando-se para quase 40\% 13 anos depois. Esta é uma força que faz com que a taxa de desocupação para as pessoas mais instruídas tenda, ao longo do tempo, estar mais pressionada do que para aquelas com nenhuma ou baixíssima instrução. 0 segundo fenômeno refere-se ao fato de que a taxa específica de atividade das pessoas menos instruídas foi a que mais caiu. Dessa maneira, duas forças se complementam para reduzir a oferta de trabalho menos qualificado no país no período

\footnotetext{
${ }^{11}$ Os valores das taxas de desocupação e ocupação por níveis de instrução não são exibidos neste trabalho, mas encontram-se disponíveis em Simões (2016).
} 
analisado: uma demográfica, relacionada à diminuição do peso dessa população na composição da PIA; e outra econômica, associada à redução da própria participação dessas pessoas no mercado de trabalho.

GRÁFICO 4

Taxas de desocupação e de atividade, por grupos etários, segundo recorte geográfico e pesquisa Brasil e regiões metropolitanas da PME - 2001-2015
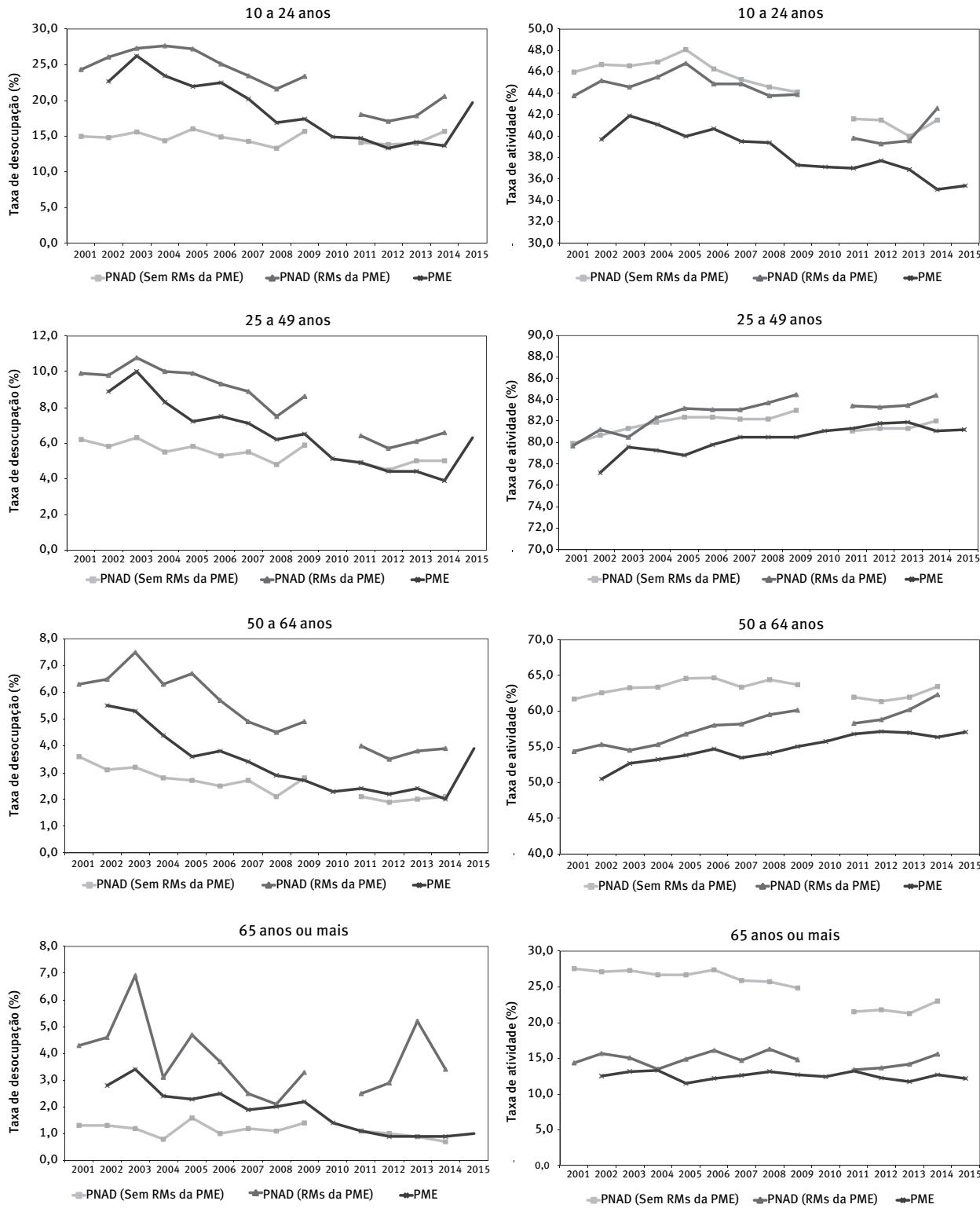

Fonte: IBGE. Pesquisa Nacional por Amostra de Domicílios e Pesquisa Mensal de Emprego. 
A taxa de atividade, quando desagregada pelo nível de instrução, exibe um padrão claro: de maneira geral, quanto mais instrução, maior é o nível da taxa de atividade. Este resultado não surpreende, já que existem grandes retornos positivos do trabalho à educação, ainda que tenham diminuído no Brasil. Ao longo do período analisado, há uma tendência de queda para todos os níveis de instrução, inclusive entre as pessoas mais instruídas. Isso revela que, se não fosse o aumento da escolaridade média da população, a taxa de atividade no país teria apresentado uma tendência de queda muito mais forte depois de 2005. No entanto, destaca-se que a redução entre as pessoas menos instruídas, especialmente aquelas com menos de oito anos de estudo (ensino fundamental incompleto ou menos), é muito mais intensa. Os custos de oportunidade envolvidos na decisão de ofertar trabalho no mercado ou trabalhar em casa explicariam tal resultado: num período marcado pelo aumento da renda, sobretudo entre as famílias mais pobres e menos instruídas, é possível que o custo de oportunidade de deixar de realizar trabalhos reprodutivos e domésticos (como cuidar de crianças e idosos ou dedicar-se à conservação da casa) seja muito alto em relação à renda adicional que estas pessoas seriam capazes de obter com o trabalho, dado seu baixo nível de instrução. Nesses casos, deixar de ofertar trabalho é uma decisão que está plenamente de acordo com a racionalidade econômica. Visando aprofundar estas análises, a variação das taxas de desocupação foi decomposta segundo duas metodologias distintas para as duas pesquisas.

\section{Decomposição da variação da taxa de desocupação}

A primeira metodologia de decomposição utilizada é macroeconômica e tem como enfoque a dinâmica dos grandes agregados e indicadores relacionados à taxa de desocupação - a população ocupada (PO), a população em idade ativa (PIA) e a taxa de atividade (TA) -, sendo baseada em trabalho apresentado em um relatório de inflação do Banco Central do Brasil (2014). A metodologia do cálculo está descrita no Quadro 1 do Anexo e os resultados desta decomposição podem ser vistos na Tabela 1.

0 efeito do crescimento da população em idade ativa sobre a taxa de desocupação, medido pelo efeito PIA, é semelhante em ambas as pesquisas. Seu efeito sobre a taxa de desocupação é positivo, indicando que o crescimento populacional impõe pressão sobre o mercado de trabalho, aumentando a taxa de desocupação. No entanto, este efeito apresenta tendência de declínio ao longo dos anos, o que reflete taxas de crescimento demográfico decrescentes.

O efeito do crescimento da ocupação (o efeito PO) é geralmente mais forte na PME, especialmente a partir de 2007. Nesta pesquisa, tal efeito é bastante significativo, sendo a grande força a trazer para baixo a taxa de desocupação no período analisado. Entretanto, em 2014 e 2015, a redução da população ocupada faz com que o efeito PO seja positivo, pressionado pelo aumento da taxa de desocupação nesses anos, indicando que a deterioração do mercado de trabalho na atual crise começou mais cedo nas metrópoles do que no 
restante do país, resultado que reforça a hipótese de que o maior dinamismo econômico das metrópoles faz com que a taxa de desocupação flutue mais nessas áreas do que no restante do país. Em 2015, o efeito PO foi positivo, e chegou a 1,5 p.p., sendo a principal força por trás do aumento de 2,0 p.p. na taxa de desocupação da PME no ano passado, que alcançou os 6,8\%. Na PNAD, o efeito PO diminui a taxa de desocupação em todos os anos da amostra, mas a intensidade parece estar se reduzindo ao longo dos anos.

TABELA 1

Decomposição da variação da taxa de desocupação por efeitos na população ocupada (PO), na população em idade ativa (PIA), na taxa de atividade (TA) e no total, na PME e PNAD Brasil - 2002-2015

Em porcentagem

\begin{tabular}{|c|c|c|c|c|c|c|c|c|}
\hline \multirow{2}{*}{ Anos } & \multicolumn{2}{|c|}{ Efeito PO } & \multicolumn{2}{|c|}{ Efeito PIA } & \multicolumn{2}{|c|}{ Efeito TA } & \multicolumn{2}{|c|}{ Efeito total } \\
\hline & PME & PNAD & PME & PNAD & PME & PNAD & PME & PNAD \\
\hline 2002 & & $-3,3$ & & 1,8 & & 1,3 & & $-0,2$ \\
\hline 2003 & & $-1,2$ & & 1,7 & & 0,1 & & 0,6 \\
\hline 2004 & $-2,6$ & $-5,0$ & 1,6 & 3,2 & 0,1 & 0,9 & $-0,9$ & $-0,9$ \\
\hline 2005 & $-2,4$ & $-2,6$ & 1,7 & 1,7 & $-0,9$ & 1,3 & $-1,6$ & 0,4 \\
\hline 2006 & $-1,8$ & $-2,0$ & 1,5 & 1,8 & 0,4 & $-0,7$ & 0,1 & $-0,9$ \\
\hline 2007 & $-2,4$ & $-1,2$ & 1,7 & 1,6 & 0,1 & $-0,6$ & $-0,7$ & $-0,3$ \\
\hline 2008 & $-3,2$ & $-2,6$ & 1,6 & 1,6 & 0,2 & $-0,1$ & $-1,4$ & $-1,0$ \\
\hline 2009 & $-0,8$ & $-0,4$ & 1,5 & 1,4 & $-0,5$ & 0,2 & 0,2 & 1,2 \\
\hline 2010 & $-3,3$ & & 1,3 & & 0,6 & & $-1,4$ & \\
\hline 2011 & $-2,0$ & $-1,0$ & 1,2 & 2,5 & 0,0 & $-3,1$ & $-0,8$ & $-1,5$ \\
\hline 2012 & $-2,1$ & $-1,3$ & 1,2 & 1,0 & 0,5 & $-0,2$ & $-0,5$ & $-0,5$ \\
\hline 2013 & $-0,7$ & $-0,5$ & 1,0 & 1,1 & $-0,4$ & $-0,3$ & $-0,1$ & 0,3 \\
\hline 2014 & 0,1 & $-2,7$ & 1,2 & 1,1 & $-1,8$ & 1,9 & $-0,5$ & 0,4 \\
\hline 2015 & 1,5 & & 1,0 & & $-0,5$ & & 2,0 & \\
\hline
\end{tabular}

Fonte: IBGE. Pesquisa Mensal de Emprego (PME) e Pesquisa Nacional por Amostra de Domicílios (PNAD).

Para a PNAD, os efeitos das variações da taxa de atividade sobre a taxa de desocupação (o efeito TA) são muito importantes. No início do período, refletindo aumentos graduais da taxa de atividade agregada, o efeito TA é positivo, mas o forte crescimento da ocupação compensa esse efeito e provoca redução da taxa de desocupação. 0 efeito TA é particularmente importante em 2011 e 2014. Na passagem de 2009 para 2011 (lembrando, mais uma vez, que a PNAD não é realizada em anos de censo demográfico), foi o forte efeito da taxa de atividade, de -3,1 p.p., que derrubou a taxa de desocupação. Se não fosse isso, o efeito PO de -1,0 p.p. não teria sido suficiente para contrapor um efeito PIA de 2,5 p.p. e a taxa de desocupação teria subido 1,6 p.p. na passagem de 2009 para 2011, chegando praticamente aos $10 \%$, contra uma taxa verificada de apenas $6,7 \%$. Isso é particularmente interessante quando se considera que este período inclui o ano de 2010, em que a economia cresceu fortemente. Era de se esperar um efeito PO mais forte.

Os efeitos no ano mais recente do período analisado, 2014, sugerem que vem aumentando novamente a entrada no mercado de trabalho, pois se verifica um efeito TA bastante elevado - o mais alto da série produzida - de 1,9 p.p. Entretanto, apesar de um efeito PO 
negativo e grande, sugerindo que um grande contingente transitou para a ocupação, este não foi suficiente para reverter os efeitos TA e PIA positivos, levando a um aumento na taxa de desocupação em 2014. É importante, entretanto, estar atento quanto à qualidade desse crescimento da ocupação da PNAD em 2014.

Para a PME, o efeito TA não é, na maior parte dos anos, muito forte. No entanto, ele é determinante a partir de 2013. A redução da taxa de atividade nestes anos segurou a taxa de desocupação, especialmente em 2014, fazendo com que a taxa de desocupação só passasse a subir em 2015, apesar de a população ocupada estar diminuindo em números absolutos desde o ano anterior. Se a taxa de atividade não tivesse variado de 2013 para 2014, a taxa de desocupação da PME teria subido 1,3 p.p., chegando aos 6,7\% já em 2014, contra o nível verificado de $4,8 \%$, que foi o mais baixo da série histórica.

A segunda metodologia de decomposição da taxa de desocupação, baseada em Barbosa Filho e Pessoa (2011), descrita Quadro 2 do Anexo, destaca como as mudanças no perfil sociodemográfico da força de trabalho influenciam a variação da taxa de desocupação. Essa metodologia permite dividir a variação total da taxa de desocupação entre dois momentos em duas componentes distintas: uma associada à variação dos níveis da taxa de desocupação, doravante denominada efeito nível; e outra relacionada à variação dos pesos de cada grupo dentro da força de trabalho, o efeito composição. Para realizar esta decomposição, foram selecionadas três características sociodemográficas consideradas mais relevantes: sexo, idade e nível de instrução. Apenas a decomposição para a PNAD é apresentada, pois a ausência da faixa de nível de escolaridade mais alto na PME (15 anos ou mais de estudo) limita a eficácia da metodologia nesta pesquisa. A decomposição é realizada para dois intervalos distintos dentro do período analisado: de 2001 até 2012, ano que marca o início do chamado "paradoxo do desemprego baixo"; e de 2012 a 2014, período em que a taxa de desocupação tem tendência de aumento nesta pesquisa, para capturar os efeitos da desaceleração da economia. Os resultados são apresentados na Tabela 2.

A taxa de desocupação no Brasil registrou queda de 3,2 pontos percentuais, entre 2001 e 2012, e aumento de 0,7 p.p, entre 2012 e 2014. No total, a redução foi de 2,5 p.p. Os resultados mostram que o efeito composição por sexo foi pouco relevante no período analisado para descrever sua variação. 0 sinal positivo indica que o efeito atuou no sentido de aumentar a taxa de desocupação. Isso ocorreu porque cresceu a participação das mulheres, que têm uma taxa de desocupação superior à dos homens. Os efeitos composição estimados são semelhantes nas regiões metropolitanas da PME e no restante do país.

A decomposição por faixas etárias exibe fortes efeitos composição, indicando que a mudança da estrutura etária da PEA é bastante importante para descrever as variações recentes da taxa de desocupação. Para o Brasil, o efeito composição por idade representou cerca de 40\% da queda observada na taxa de desocupação da PNAD entre 2001 e 2014. O efeito composição por idade é um pouco mais forte nas regiões metropolitanas da PME do que no restante do país, o que está associado a um perfil mais maduro nas metrópoles, 
mas, como a queda total da taxa de desocupação foi mais intensa nestas regiões, o efeito descreve menos da variação nelas, ao redor de $25 \%$.

TABELA 2

Decomposição da variação da taxa de desocupação por sexo, grupo etário e nível de instrução, por tipo de efeito, segundo amostras

Brasil - 2001-2014

Em porcentagem

\begin{tabular}{|c|c|c|c|}
\hline Amostras & Efeito nível & Efeito composição & Efeito total \\
\hline \multicolumn{4}{|l|}{ Sexo } \\
\hline Brasil (2001-2012) & $-3,2$ & 0,1 & $-3,2$ \\
\hline Brasil (2012-2014) & 0,7 & 0,0 & 0,7 \\
\hline Brasil (2001-2014) & $-2,5$ & 0,1 & $-2,5$ \\
\hline RMs da PME (2001-2012) & $-5,8$ & 0,1 & $-5,7$ \\
\hline RMs da PME (2012-2014) & 1,2 & 0,0 & 1,2 \\
\hline RMs da PME (2001-2014) & $-4,6$ & 0,1 & $-4,5$ \\
\hline Brasil sem RMs da PME (2001-2012) & $-2,3$ & 0,1 & $-2,3$ \\
\hline Brasil sem RMs da PME (2012-2014) & 0,5 & 0,0 & 0,5 \\
\hline Brasil sem RMs da PME (2001-2014) & $-1,8$ & 0,1 & $-1,8$ \\
\hline \multicolumn{4}{|l|}{ Grupo etário } \\
\hline Brasil (2001-2012) & $-2,3$ & $-0,8$ & $-3,2$ \\
\hline Brasil (2012-2014) & 0,8 & $-0,2$ & 0,7 \\
\hline Brasil (2001-2014) & $-1,5$ & $-1,0$ & $-2,5$ \\
\hline RMs da PME (2001-2012) & $-4,6$ & $-1,1$ & $-5,7$ \\
\hline RMs da PME (2012-2014) & 1,2 & 0,0 & 1,2 \\
\hline RMs da PME (2001-2014) & $-3,3$ & $-1,2$ & $-4,5$ \\
\hline Brasil sem RMs da PME (2001-2012) & $-1,5$ & $-0,8$ & $-2,3$ \\
\hline Brasil sem RMs da PME (2012-2014) & 0,7 & $-0,2$ & 0,5 \\
\hline Brasil sem RMs da PME (2001-2014) & $-0,8$ & $-0,9$ & $-1,8$ \\
\hline \multicolumn{4}{|l|}{ Nível de instrução } \\
\hline Brasil (2001-2012) & $-3,4$ & 0,2 & $-3,2$ \\
\hline Brasil (2012-2014) & 0,7 & 0,0 & 0,7 \\
\hline Brasil (2001-2014) & $-2,7$ & 0,2 & $-2,5$ \\
\hline RMs da PME (2001-2012) & $-5,1$ & $-0,7$ & $-5,7$ \\
\hline RMs da PME (2012-2014) & 1,3 & $-0,1$ & 1,2 \\
\hline RMs da PME (2001-2014) & $-3,8$ & $-0,7$ & $-4,5$ \\
\hline Brasil sem RMs da PME (2001-2012) & $-2,7$ & 0,4 & $-2,3$ \\
\hline Brasil sem RMs da PME (2012-2014) & 0,5 & 0,0 & 0,5 \\
\hline Brasil sem RMs da PME (2001-2014) & $-2,2$ & 0,4 & $-1,8$ \\
\hline
\end{tabular}

Fonte: IBGE. Pesquisa Mensal de Emprego (PME) e Pesquisa Nacional por Amostra de Domicílios (PNAD).

Para as demais regiões do país, onde os níveis de desocupação caíram menos, o efeito da mudança de estrutura etária descreve mais de $50 \%$ da queda total da taxa de desocupação. Por trás da magnitude desses efeitos está, principalmente, a redução do peso dos jovens na PEA: entre 2001 e 2014, a participação das pessoas com idade entre 10 e 24 anos diminuiu de $27,3 \%$ para $19,2 \%$, no Brasil, de $24,8 \%$ para $17,6 \%$, nas RMs da PME, e de $28,1 \%$ para $19,8 \%$, no restante do país. É relevante destacar que o efeito composição 
é significativo até mesmo no curto período de 2012 a 2014 (-0,2\%.), ajudando a atenuar a subida da taxa de desocupação no atual contexto de crise econômica.

Os resultados da decomposição por nível de instrução (Tabela 2) podem surpreender à primeira vista, pois são de baixa intensidade e apontam em direções opostas nas regiões metropolitanas da PME e no restante do país: diminui a taxa de desocupação nas metrópoles e aumenta nas demais regiões do país (predominando este efeito para o Brasil como um todo). Como isso pode ocorrer dado o avanço da educação nos últimos anos? A resposta está na relação não linear entre a educação medida por anos de estudo e a taxa de desocupação. A taxa de desocupação apresenta uma forma de parábola voltada para baixo em relação ao nível educacional, ou seja, é baixa para os níveis extremos da escolaridade e mais alta para os intermediários. A análise das mudanças da composição da PEA por nível de instrução no país mostra que diminuiu sensivelmente a participação de pessoas com menos anos de educação e aumentou a das mais educadas. Em 2001, apenas $29 \%$ da população economicamente ativa tinha 11 anos ou mais de estudo, isto é, pelo menos o ensino médio completo. Em 2014, entretanto, esta participação havia subido para 50\%. 0 avanço da participação das pessoas com pelo menos 15 anos de estudo - ensino superior completo - foi grande: de 6,7\%, em 2001, para 13,0\% da PEA, em 2014, o que ainda é pouco. Ou seja, a educação avançou na força de trabalho brasileira, mas ainda se encontra predominantemente em níveis intermediários, para os quais as taxas de desocupação específicas são muito altas, particularmente mais elevadas do que para os níveis mais baixos que tiveram sua participação reduzida. Tal fato explica o efeito composição positivo estimado.

Nas regiões metropolitanas da PME, não apenas o avanço da participação das pessoas com 15 anos ou mais de educação é maior do que no restante do país, como também a taxa específica de desocupação das pessoas na categoria de 11 a 14 anos de estudo não é tão alta, explicando o efeito composição negativo estimado para estas regiões. Espera-se que avanços adicionais para níveis mais altos de educação, para os quais as taxas específicas de desocupação são menores, tendam a diminuir a taxa de desocupação do Brasil no futuro, como já ocorre nas metrópoles da PME. Para tanto, é necessário ampliar o acesso à educação superior no país.

0 avanço da educação superior e da qualificação da mão de obra é um dos fatores considerados essenciais não apenas para que as taxas de desocupação caiam, mas também para que se aumente a produtividade do trabalho e seja impulsionado o crescimento no país, especialmente num contexto demográfico que não será tão favorável ao crescimento por muito mais tempo.

\section{Perspectivas para o aproveitamento do bônus demográfico no Brasil}

Sabe-se que a possibilidade de o Brasil desfrutar os últimos benefícios do bônus demográfico depende de uma dinâmica favorável do mercado de trabalho. Também 
chamado de dividendo demográfico (ou janela de oportunidade demográfica), trata-se de um fenômeno que só ocorre uma vez ao longo da história de uma sociedade, em que a estrutura etária da população favorece o aumento da renda per capita e o crescimento econômico (MARTINE; CARVALHO; ARIAS, 1994; CARVALHO; WONG, 1995). Entretanto, essa janela de oportunidade só pode contribuir para a solução dos problemas sociais do país se a economia for capaz de empregar a mão de obra disponível de modo eficiente e produtivo (TURRA; QUEIROZ, 2005; RIOS-NETO, 2005; ALVES; BRUNO, 2006). Isto é, entender a dinâmica recente do mercado de trabalho é também fundamental para uma análise mais completa do aproveitamento do bônus demográfico e da potencialidade de crescimento da economia brasileira nos próximos anos.

Na conjuntura atual, o Brasil está deixando de colher os últimos frutos oferecidos por uma situação demográfica ainda favorável, já que as falhas de política econômica estão contribuindo para o fim precoce do bônus demográfico. Ao contrário do que poderia se intuir pelo péssimo momento da economia, o Brasil está passando pelo melhor momento do seu bônus, com baixa razão de dependência. Porém, esta vai começar a subir inevitavelmente, o que pressionará ainda mais uma já combalida economia.

As mudanças recentes no mercado de trabalho expostas ao longo deste trabalho têm influência direta sobre as perspectivas para o aproveitamento do bônus demográfico. Um exemplo importante disso está na dinâmica da taxa de atividade das mulheres. Após décadas de aumentos, ela parou de crescer. Isso é preocupante, pois grande parte do bônus demográfico brasileiro foi um bônus de participação feminina (ALVES; CAVENAGHI, 2016). A população economicamente ativa como proporção da população total cresceu de pouco mais de $30 \%$, no início da década de 1970 , para quase $50 \%$, em 2010 , segundo dados dos censos demográficos, e os números revelam que as mulheres foram responsáveis por nada menos que $85 \%$ deste aumento.

Os dados da PNAD também mostram uma diferença marcante entre homens e mulheres no que diz respeito à relação entre o nível de instrução e a taxa de atividade. Como visto anteriormente, para ambos os sexos, a taxa de atividade é positivamente relacionada com o nível de instrução, mas esta relação é ainda mais forte entre as mulheres. Na passagem da categoria de 11 até 14 anos de estudo (ensino médio completo ou superior incompleto) para a mais alta, de 15 anos ou mais de estudo (ensino superior completo), a taxa de atividade tem um crescimento substancial para as mulheres, de menos de $70 \%$ para cerca de $80 \%$, mas quase não aumenta para os homens, permanecendo ao redor dos $85 \%$. Se assumirmos como desejável elevar a taxa de atividade da economia para que o país possa desfrutar os últimos benefícios do bônus demográfico, promover a conclusão do ensino superior entre as mulheres, dessa maneira, garante um retorno ainda maior.

No livro Até onde caminhou a revolução de gênero no Brasil?, organizado pelo Grupo de Trabalho População e Gênero da Associação Brasileira de Estudos Populacionais 
(ITABORAI; RICOLDI, 2016), há um debate importante sobre o fim do bônus demográfico feminino. Numa perspectiva pessimista, Alves (2016) considera que a perda de dinamismo do mercado de trabalho, a partir de 2013, e a recessão econômica interromperam seis décadas de aumento da taxa de ocupação das mulheres, reduzindo, inclusive, o percentual daquelas com curso superior nas atividades produtivas. A crise atual está revertendo o processo de inserção feminina no mercado de trabalho e estreitando a janela de oportunidade para se atingir uma maior paridade de gênero na taxa de ocupação, antes que o envelhecimento populacional reduza, em termos absolutos e relativos, a população em idade ativa. Numa perspectiva mais otimista, Wajnman (2016) considera que a crise econômica tem, de fato, um efeito desastroso no curto prazo, mas, no longo prazo, os efeitos de composição provocados pela maior escolaridade feminina devem elevar a participação das mulheres na força de trabalho.

Além dessa problemática, outra questão importante nesse contexto é o fenômeno "nem-nem", dos jovens que não estudam e nem trabalham. A queda da participação dos jovens, que tem um caráter positivo se estes estiverem saindo do mercado de trabalho para aumentar sua escolaridade, pode ser extremamente negativa se não estiverem aumentando seu capital humano. Os dados revelam que, de fato, aumentou o número de jovens inativos que estudam. No entanto, cresceu também o número de jovens inativos que não trabalham. Segundo dados da PNAD, em 2005, 13,9\% dos jovens entre 18 e 24 anos se encontravam na condição “nem-nem”. Em 2014, este grupo representava 15,7\%. Na PME, o aumento é ainda mais notável: de 13,4\%, em 2006, os jovens “nem-nem" passaram a ser 17,3\%, em 2015.

Os jovens também vêm sendo afetados de maneira mais severa na atual crise, o que piora ainda mais as perspectivas de aproveitamento da janela de oportunidade demográfica. Isso é extremamente preocupante, porque se espera que coortes menores tenham mais oportunidades de acesso à educação e ao trabalho (EASTERLIN, 1975), o que reforçaria a dinâmica favorável que caracteriza o período do bônus demográfico e promoveria a inclusão de adolescentes e jovens. Entretanto, não é o que temos verificado no Brasil. Este grupo tem sido proporcionalmente mais afetado do que as pessoas mais velhas dentro da PIA. A taxa de desocupação agregada caiu de $9,4 \%$ em 2001 para 7,1\% em 2008 e, mesmo após dois anos seguidos de aumento, chegou a $6,9 \%$ em 2014. Há, portanto, uma tendência geral de queda no período analisado.

Porém, o Gráfico 5, que apresenta as taxas específicas de desocupação por idade, mostra que esta queda foi muito heterogênea entre os grupos etários. Em 2014, as taxas específicas de desocupação para pessoas de 20 anos ou mais são menores do que em 2001 e estão muito próximas às de 2008. Entretanto, os grupos de 10 a $14 \mathrm{e}$ de 15 a 19 anos registram, em 2014, as taxas específicas mais altas de todo o período analisado. Isto é, a taxa agregada mais baixa para o último ano esconde uma composição etária muito mais desfavorável aos jovens. 
GRÁFICO 5

Taxas específicas de desocupação, por grupos etários quinquenais

Brasil - 2001-2014

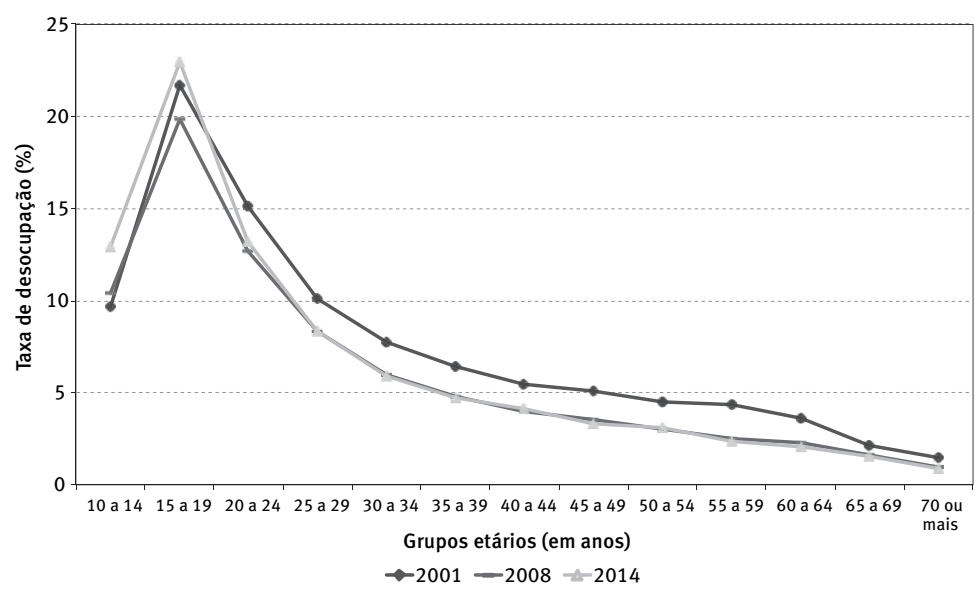

Fonte: IBGE. Pesquisa Nacional por Amostra de Domicílios.

\section{Considerações finais}

Este artigo procurou analisar, à luz das recentes transformações sociais, econômicas e demográficas da população, o mercado de trabalho no Brasil, principalmente no período em que vigorou o chamado "paradoxo do baixo desemprego".

Observou-se que, apesar de representarem apenas um quarto da população em idade ativa do país, as regiões metropolitanas da PME foram responsáveis por metade da queda na taxa de desocupação nacional verificada nos dados da PNAD entre 2003 e 2012. Em compensação, é nas metrópoles que a taxa de desocupação tem crescido com mais intensidade no atual contexto de crise. Levanta-se a hipótese de que este comportamento pode ser atribuído ao fato de as transferências governamentais, os aumentos reais do salário mínimo e os programas sociais tornarem as economias das cidades pequenas menos sensíveis às flutuações macroeconômicas. Este é um tema que pode ser abordado de maneira mais pormenorizada em estudos futuros, por meio de técnicas estatísticas adequadas.

Verificou-se que os movimentos da taxa de atividade e a redução do crescimento populacional foram fundamentais na determinação das taxas de desocupação no período recente no Brasil. A taxa de atividade caiu principalmente entre os homens, as pessoas menos instruídas e os mais jovens. Os dados mostram que diminuiu consideravelmente a taxa de atividade entre os jovens que estudam, mas esta vem se reduzindo também para os que não estudam.

0 chamado paradoxo do mercado do trabalho no Brasil, em evidência principalmente entre 2012 e 2014, foi muito mais marcante nos dados da PME do que nos da PNAD. Na verdade, a taxa de desocupação pela PNAD não apresenta um comportamento tão disfuncional em sua relação com o crescimento econômico. Credita-se ao fato de a PME ser 
uma pesquisa de acompanhamento conjuntural o grande destaque que o paradoxo do desemprego recebeu na imprensa e nos meios acadêmicos.

A composição etária da população explica grande parte da queda do desemprego no período analisado que precede a atual crise. Não fosse este efeito, o aumento da taxa de desocupação teria sido ainda maior no atual ciclo de alta desta taxa. A mudança na composição etária da população economicamente ativa descreve cerca de $40 \%$ da sua variação no período estudado para o país como um todo. As mudanças da escolaridade e da composição por sexo da força de trabalho descrevem pouco da variação da taxa de desocupação, apresentando efeitos composição baixos para o Brasil como um todo. Entretanto, é importante destacar que os efeitos da escolaridade são bastante distintos entre as regiões metropolitanas da PME e o restante do país.

A interrupção da tendência do aumento da taxa de atividade feminina desperta preocupações, uma vez que grande parte do bônus demográfico brasileiro tem sido um bônus feminino. $E$, tendo em vista que impulsos maiores na taxa de atividade graças ao avanço da educação superior se dão mais fortemente entre as mulheres do que entre os homens, estas preocupações ganham ainda mais corpo.

Os jovens têm sido proporcionalmente mais prejudicados no contexto da atual crise, e a desocupação tem hoje um perfil etário ainda mais desfavorável aos mais jovens do que no passado. Isso levanta preocupações do ponto de vista social e econômico, pois estes jovens excluídos do mercado de trabalho adquirem menos habilidades que podem impulsionar sua produtividade no futuro. Justificam-se, dessa maneira, os temores de que esta possa ser uma "geração perdida", mais educada do que qualquer outra na história do país, mas que corre sérios riscos de não alcançar o máximo de suas possibilidades, tanto em termos de contribuição para o crescimento econômico quanto de realizações pessoais e projetos de vida.

Indicadores como o nível de ocupação da economia desabaram por conta da crise, justamente em um momento em que a estrutura etária favoreceria a inserção produtiva da população, principalmente da que sempre esteve marginalmente ligada à estrutura produtiva, como os jovens e as mulheres. São grandes as possibilidades de que haja uma segunda década perdida, com aumento do desemprego e estagnação da renda per capita. Em resumo, para uma economia que gera poucas oportunidades, não há bônus demográfico que ajude. Ou paradoxo que dure para sempre.

\section{Referências}

ALVES, J. E. D. Crise no mercado de trabalho, bônus demográfico e desempoderamento feminino. In: ITABORAI, N. R.; RICOLDI, A. M. (Org.). Até onde caminhou a revolução de gênero no Brasil? Belo Horizonte: Abep, 2016. p. 21-44.

ALVES, J. E. D.; BRUNO, M. A. P. População e crescimento de longo prazo no Brasil: como aproveitar a janela de oportunidade demográfica? In: ENCONTRO NACIONAL DE ESTUDOS POPULACIONAIS, 15. Anais... Caxambu: Abep, 2006. 
ALVES, J. E. D.; CAVENAGHI, S. A estagnação da taxa de ocupação e o fim precoce do bônus demográfico. In: VII CONGRESSO DA ASSOCIAÇÃO LATINO-AMERICANA DE POPULAÇÃO, XX ENCONTRO NACIONAL DE ESTUDOS POPULACIONAIS. Anais... Foz do Iguaçu: Alap/Abep, 2016.

BANCO CENTRAL DO BRASIL. Indicadores não tradicionais do mercado de trabalho. Relatório de Inflação, v. 14, n. 2, p. 102-107, junho 2012.

. Decomposição da evolução da taxa de desemprego. Relatório de Inflação, v. 16, n. 3, p. 16-18, setembro 2014

BARBOSA FILHO, F. D. H.; PESSÔA, S. Uma análise da redução da taxa de desemprego. In: XXXIX ENCONTRO NACIONAL DE ECONOMIA DA ANPEC. Anais... Foz do Iguaçu: Anpec, 2011.

BARBOSA, A. L. N. de H. Um retrato de duas décadas do mercado de trabalho brasileiro. In: CAMARANO, A. A. (Org.). Novo regime demográfico: uma nova relação entre população e desenvolvimento? Rio de Janeiro: Ipea, 2014a. p. 271-313.

Participação feminina na força de trabalho brasileira: evolução e determinantes. In: CAMARANO, A. A. (Org.). Novo regime demográfico: uma nova relação entre população e desenvolvimento? Rio de Janeiro: Ipea, 2014b. p. 407-442.

BLANCHARD, O. Macroeconomia. 4. ed. São Paulo: Pearson Prentice Hall, 2007.

BRITTO, T.; MEDEIROS, M.; SOARES, F. Targeted cash transfer programmes in Brazil: BPC and the Bolsa Familia. Brasilia: International Poverty Centre, n. 46, p. 22, 2008.

CARVALHO, J. A. M.; WONG, L. R. A window of opportunity: some demographic and socioeconomic implications of the rapid fertility decline in Brazil. Belo Horizonte: Cedeplar, UFMG, 1995 (Working paper).

CORSEUIL, C. Decifrando alguns paradoxos do mercado de trabalho brasileiro. Revista Desafios do Desenvolvimento, ano 12, edição 83, 2015.

CORSEUIL, C. H. L.; RAMOS, L. Sobre a comparação da taxa de desocupação na PNAD Contínua e na PME. Brasília: Ipea, abril 2014.

CORSEUIL, C. H. L.; REIS, M. Há viés de painel rotativo na taxa de desocupação da PME? Mercado de Trabalho, n. 58, ano 21, p. 27-34, abr. 2015.

DORNBUSCH, R.; FISCHER, S. Macroeconomia. 5. ed. São Paulo: Pearson Prentice Hall, 2006.

EASTERLIN, R. An economic framework for fertility analysis. Studies in Family Planing, v. 6, p. 54-63, 1975.

GOLDFAJN, I. Para onde vai o desemprego? O Globo, 04 mar. 2014. Disponível em: <http://oglobo. globo.com/opiniao/para-onde-vai-desemprego-11752598〉. Acesso em: 22 out. 2016.

ITABORAI, N. R.; RICOLDI, A. M. (Org.). Até onde caminhou a revolução de gênero no Brasil? Belo Horizonte: Abep, 2016.

MARTINE, G.; CARVALHO, J. A. M.; ARIAS, A. R. Mudanças recentes no padrão demográfico brasileiro e implicações para a agenda social. Brasília: Ipea, 1994 (Texto para discussão, 345).

NERI, M. O desemprego no censo: a febre e o termômetro. Revista Conjuntura Econômica, v. 56, n. 3, p. 54-63, 2002.

PAIM, A. B. Testes cognitivos. In: $7^{\circ}$ ENCONTRO COMEQ - IBGE. Rio de Janeiro, 2016.

RAMOS, L. 0 desempenho recente do mercado de trabalho no Brasil. Rio de Janeiro: Ipea, 2007 (Texto para discussão, 1255).

RIBEIRO, M. G. Estrutura social e desigualdade de renda: uma comparação entre os municípios metropolitanos e os não metropolitanos do Brasil entre 2000 e 2010. Revista Brasileira de 
Estudos de População, v. 33, n. 2, p. 237-256, maio/ago. 2016. Disponível em: 〈http://dx.doi. org/10.20947/S0102-30982016a0010>. Acesso em: 20 out. 2016.

RIOS-NETO, E. L. G. Questões emergentes na análise demográfica: o caso brasileiro. Revista Brasileira de Estudos de População, v. 22, n. 2, p. 371-408, jul./dez. 2005.

SIMÕES, P. H. C. Transformações e tendências do mercado de trabalho no Brasil de 2001 a 2015 e o paradoxo do baixo desemprego com desaquecimento da atividade econômica. Dissertação (Mestrado) - Escola Nacional de Ciências Estatísticas - Ence/IBGE, Rio de Janeiro, 2016.

TEIXEIRA, C. G. O Programa Bolsa Família e a oferta de trabalho: uma perspectiva de choque orçamentário. [S.I.]: UFMG, 2009.

TURRA, C. M.; QUEIROZ, B. L. Before it's too late: demographic transition, labour supply and social security problems in Brazil. United Nations Expert Group Meeting on Social and Economic Implications of Changing Population Age Structures. México, Departamento de Assuntos Econômicos e Sociais, Divisão de População, 2005.

WAJNMAN, S. "Quantidade" e "qualidade" da participação das mulheres na força de trabalho brasileira. In: ITABORAI, N. R.; RICOLDI, A. M. (Org.). Até onde caminhou a revolução de gênero no Brasil? Belo Horizonte: Abep, 2016. p. 45-58.

\section{Sobre os autores}

Pedro Henrique de Castro Simões é mestre em População, Território e Estatísticas Públicas pela Escola Nacional de Ciências Estatísticas (Ence), do Instituto Brasileiro de Geografia e Estatística (IBGE) e bacharel em Economia pela Pontifícia Universidade Católica do Rio de Janeiro (PUC-Rio). Consultor da SLQ - Soluções Quantitativas.

José Eustáquio Diniz Alves é doutor em Demografia pelo Centro de Desenvolvimento e Planejamento Regional (Cedeplar) da Universidade Federal de Minas Gerais (UFMG), com pós-doutorado no Núcleo de Estudos de População (Nepo), da Universidade Estadual de Campinas (Unicamp). Professor titular do Programa de Pós-graduação em População, Território e Estatísticas Públicas da Escola Nacional de Ciências Estatísticas (Ence), do Instituto Brasileiro de Geografia e Estatística (IBGE).

Pedro Luis do Nascimento Silva é doutor em Estatística pela Universidade de Southampton, Inglaterra, mestre em Estatística pelo Instituto de Matemática Pura e Aplicada e bacharel em Estatística pela Escola Nacional de Ciências Estatísticas (Ence), do IBGE. Pesquisador titular do Programa de Pós-graduação em População, Território e Estatísticas Públicas da Ence/IBGE.

\section{Endereço para correspondência}

Pedro Henrique de Castro Simões

Escola Nacional de Ciências Estatísticas

Rua André Cavalcanti, 106, sala 109, Bairro de Fátima

20231-050 - Rio de Janeiro-RJ, Brasil

José Eustáquio Diniz Alves

Escola Nacional de Ciências Estatísticas

Rua André Cavalcanti, 106, sala 502, Bairro de Fátima

20231-050 - Rio de Janeiro-RJ, Brasil

Pedro Luis do Nascimento Silva

Escola Nacional de Ciências Estatísticas

Rua André Cavalcanti, 106, sala 503-C, Bairro de Fátima

20231-050 - Rio de Janeiro-RJ, Brasil 


\begin{abstract}
Transformations and tendencies of the labor market in Brazil between 2001 and 2015: paradox of the low unemployment?
\end{abstract}

The Brazilian economy, boosted by the commodities super-cycle, had a decade of growth and macroeconomic stability, in which the labor market performed very favorably. However, there was a slowdown in the GDP, followed by a strong recession in 2015 and 2016. There was a large gap between the beginning of the economic slowdown and its first effects on the labor market, the so called paradox of low unemployment. The objective of this paper is to analyze this phenomenon using the two main surveys carried out by the Brazilian Geography and Statistics Institution (IBGE) that deals with this subject, the Pesquisa Nacional por Amostra de Domicilios (PNAD) and the Pesquisa Mensal de Emprego (PME). Using the unemployment rate variation decomposition methodology, the results show that the most expressive part of both, the previous reduction and the current increase of the rate, took place in the metropolitan areas, and that a great part of this behavior can be explained by the reduction of the participation of both young and less educated workers and the reduction in the pace of women' insertion in the labor market. The age profile of unemployment in Brazil has become younger, raising concerns of an emerging “lost generation".

Keywords: Labor market. Unemployment. Youth. Unemployment paradox. Unemployment rate decomposition.

\title{
Resumen
}

Cambios y tendencias en el mercado de trabajo en Brasil entre 2001 y 2015: la paradoja bajo nivel de desempleo?

La economía brasileña, favorecida por el superciclo de las comodities, tuvo una década de crecimiento y estabilidad macroeconómica, en la cual el mercado laboral mostró un relativo comportamiento favorable. Sin embargo, hubo una desaceleración del producto interno bruto (PIB) seguida de una profunda recesión en 2015 y 2016. En este período, hubo un profundo desfasaje entre el inicio de la crisis económica y sus primeros efectos en el mercado de trabajo - la llamada paradoja de la baja tasa de desempleo-. El objetivo de este artículo es analizar este fenómeno, utilizando las dos encuestas principales del Instituto Brasileño de Geografía y Estadística (IBGE) que abordan el tema de empleo: la Pesquisa Nacional por Amostra de Domicílios (PNAD) y la Pesquisa Mensal de Emprego (PME). Utilizando la metodología de descomposición de la variación de la tasa de desempleo, se encontró que la porción más significativa, tanto de la reducción previa de la tasa de desempleo cuanto de su actual aumento, se produjo en las regiones metropolitanas y que gran parte de su comportamiento puede ser explicado por la reducción de la participación de los más jóvenes, de los menos educados y por la reducción de la tasa de participación de las mujeres en el mercado laboral. El perfil de edad de desempleo en el país se ha rejuvenecido, lo que plantea preocupaciones acerca de la aparición de una "generación perdida".

Palabras clave: Mercado de trabajo. Desempleo. Juventud. Paradoja del desempleo. Descomposición de la tasa de desempleo. 


\section{Anexo}

\section{QUADRO 1}

Método de decomposição da taxa de desocupação - 1

Esta decomposição baseia-se nas definições de taxa de desocupação (TD) e taxa de atividade (TA):

$$
T D_{t}=\frac{P D_{t}}{P E A_{t}} \quad T A_{t}=\frac{P E A_{t}}{P I A_{t}}
$$

Em que $T D$ é a taxa de desocupação, $P D$ é a população desocupada, $P E A$ é a população economicamente ativa, $T A$ é a taxa de atividade e PIA é a população em idade ativa no período t. Levando em consideração que:

$$
P E A_{t}=P D_{t}+P O_{t}
$$

Em que $P O$ é a população ocupada. Isolando $P D$ na equação acima, é possivel obter:

Derivando a expressão acima se obtêm:

$$
T D_{t}=1-\frac{P O_{t}}{T A_{t} \cdot P I A_{t}}
$$

$$
\begin{gathered}
d T D_{t}=\frac{\partial T D_{t}}{\partial P O_{t}} \cdot d P O_{t}+\frac{\partial T D_{t}}{\partial P I A_{t}} \cdot d P I A_{t}+\frac{\partial T D_{t}}{\partial T A_{t}} \cdot d T A_{t} \\
d T D_{t}=-\left(1-T D_{t}\right) \frac{d P O_{t}}{P O_{t}}+\left(1-T D_{t}\right) \frac{d P I A_{t}}{P I A_{t}}+\left(1-T D_{t}\right) \frac{d T A_{t}}{T A_{t}}
\end{gathered}
$$

Reescrevendo a equação acima de maneira discreta, tem-se:

$$
\Delta T D_{t}=-\left(1-T D_{t-1}\right) \frac{\Delta P O_{t}}{P O_{t-1}}+\left(1-T D_{t-1}\right) \frac{\Delta P I A_{t}}{P I A_{t-1}}+\left(1-T D_{t-1}\right) \frac{\Delta T A_{t}}{T A_{t-1}}
$$

Onde os termos à direta da equação representam, respectivamente, decomposição da variação da taxa de desocupação em efeito população ocupada $(\triangle P O)$, em efeito população em idade ativa $(\triangle P I A)$ e em efeito taxa de atividade $(\triangle T A)$. 


\section{QUADRO 2}

Método de decomposição da taxa de desocupação - 2

A taxa de desocupação agregada (TD) pode ser decomposta pela participação de cada grupo da força de trabalho segundo diversas características sociais, econômicas e demográficas. Denotando cada grupo pela letra $i$ e o período pela letra $t$, tem-se:

$$
T D_{t}=\frac{P D_{t}}{P E A_{t}}=\sum_{i} \phi_{t, i} T D_{t-1}
$$

Em que a participação de cada grupo na PEA é dada por:

$$
T D_{t, i}=\frac{P E A_{t, i}}{P E A_{t}}
$$

Isto é, a taxa de desocupação agregada em um período é a soma das taxas de desocupação de cada grupo $i$, ponderadas pelos seus respectivos pesos na população economicamente ativa. Assim, a diferença da taxa de desocupação agregada entre dois períodos $t$ e $t-1$ pode ser escrita da seguinte forma:

$$
\begin{gathered}
T D_{t}-T D_{t-1}=\sum_{i}\left(\phi_{t, i} T D_{t, i}-\phi_{t-1, i} T D_{t-1, i}\right) \\
T D_{t}-T D_{t-1}=1 / 2 \sum_{i}\left(\phi_{t, i} T D_{t, i}-\phi_{t-1, i} T D_{t-1, i}\right)+1 / 2 \sum_{i}\left(\phi_{t, i} T D_{t, i}-\phi_{t-1, i} T D_{t-1, i}\right)
\end{gathered}
$$

Somando e subtraindo $\Phi_{t, i} T D_{t-1, i}$ do primeiro parêntese e fazendo o mesmo com $\Phi_{t-1, i} T D_{t, i}$ no segundo parêntese tem-se:

$$
\begin{array}{r}
=1 / 2 \sum_{i}\left[\phi_{t, i}\left(T D_{t, i}-T D_{t-1, i}\right)+T D_{t-1, i}\left(\phi_{t, i}-\phi_{t-1, i}\right)\right] \\
+1 / 2 \sum_{i}\left[\phi_{t, i-1}\left(T D_{t, i}-T D_{t-1, i}\right)+T D_{t-1, i}\left(\phi_{t, i}-\phi_{t-1, i}\right)\right] \\
=\sum_{i} \frac{\phi_{t, i}-\phi_{t-1, i}}{2}\left(T D_{t, i}-T D_{t-1, i}\right)+\sum_{i} \frac{T D_{t, i}-T D_{t-1, i}}{2}\left(\phi_{t, i}-\phi_{t-1, i}\right)
\end{array}
$$

Recebido para publicação em 05/11/2016 Recomendado para publicação em 06/12/2016 Aceito para publicação em 21/12/2016 